\title{
Dramatização de histórias: A conquista de leitores por meio da Educação Estético-Ambiental
}

\author{
Juego de roles de la historia: la conquista de los lectores a través de la \\ educacion estético-ambiental
}

Story Role Playing: The Readers' Conquest Through AestheticEnvironmental Education

\author{
Juliana Duarte Simões ${ }^{1}$ \\ Luciana Netto Dolci ${ }^{2}$
}

\begin{abstract}
Resumo
O presente trabalho traz como temática a Educação Estético-Ambiental e suas relações com a conquista de leitores desde a Educação Infantil, para tanto, apresentamos como possibilidade dessa perspectiva de educação, as dramatizações de histórias de Literatura Infantil para crianças como uma prática pedagógica que pode gerar experiências significativas capazes de desenvolver o gosto pela leitura, bem como auxiliar na prática educativa transformadora. Acreditamos enquanto educadoras que a Educação Estético-Ambiental é "um mundo de possibilidades" (DOLCI, 2014, p. 32) e que com ela conseguimos garantir o desenvolvimento das dimensões humanas. Nosso objetivo é refletir e analisar as relações construídas pelos sujeitos acerca das experiências vividas com a dramatização de histórias, bem como o desenvolvimento desses sujeitos, após o término do projeto. Este trabalho advém de um projeto intitulado "Quem conta, reconta, faz de conta", que teve duração de dez semanas, em uma turma com onze crianças de nível dois da Educação Infantil, em uma escola pública municipal situada no município de Rio Grande. Trata-se de uma pesquisa de cunho qualitativo, com investigação do tipo exploratória, com procedimentos de intervenção pedagógica, buscando um repensar na ação educacional e utiliza a análise de conteúdo para analisar os dados gerados. Como resultado da análise dos trazemos três categorias, a saber: A importância da literatura infantil nas infâncias; Por que dramatizar histórias para as crianças?; Os avanços percebidos ao longo da pesquisa. Concluímos o trabalho trazendo as considerações sobre a conquista de leitores desde a Educação Infantil.
\end{abstract}

Palavras-Chave: Conquista de Leitores; Dramatização de histórias; Educação Estético-Ambiental; Educação Infantil; Literatura Infantil.

\section{Resumen}

El presente trabajo tiene como tema la Educación Estética-Ambiental y sus relaciones con la conquista de los lectores desde la Educación de la Primera Infancia, con este fin, presentamos como una posibilidad de esta perspectiva de la educación, la dramatización de cuentos de literatura infantil para niños como una práctica pedagógica que puede generar experiencias significativas capaces de desarrollar un gusto por la lectura, así como ayudar en la práctica educativa transformadora. Creemos como educadores que la Educación Estética-Ambiental es "un mundo de posibilidades" (DOLCI, 2014, p. 32) y que con ella podemos garantizar el desarrollo de las dimensiones humanas. Nuestro objetivo es reflejar y analizar las relaciones construidas por los sujetos sobre sus experiencias con la dramatización de historias, así como el desarrollo de estos temas, después del final del

\footnotetext{
1 Mestranda em Educação Ambiental; Programa de Pós-Graduação em Educação Ambiental; Universidade Federal do Rio Grande - FURG; Bolsista CAPES; Rio Grande, RS, Brasil; jujuzynha1203-m@ hotmail.com

2 Doutora em Educação Ambiental; Professora adjunta do Instituto de Educação e do Programa de PósGraduação em Educação Ambiental - PPGEA na Universidade Federal do Rio Grande - FURG; Rio Grande, RS, Brasil; lndolci@hotmail.com
} 
proyecto. Este trabajo proviene de un proyecto titulado "Quién cuenta, cuenta, hace creer", que duró diez semanas en una clase con once niños del nivel dos de Kindergarten, en una escuela pública municipal ubicada en la ciudad de Río Grande. Esta es una investigación cualitativa, con investigación exploratoria, con procedimientos de intervención pedagógica, que busca repensar la acción educativa y utiliza el análisis de contenido para analizar los datos generados. Como resultado del análisis, traemos tres categorías, a saber: la importancia de la literatura infantil en la infancia; ¿Por qué historias de juegos de rol para niños? Los avances percibidos a lo largo de la investigación. Concluimos el tra/bajo trayendo las consideraciones sobre la conquista de los lectores desde la educación de la primera infancia.

Palabras claves: Conquista de lectores; Juego de roles de historia; Educación Estética-Ambiental; Educación Infantil; Literatura infantil.

\begin{abstract}
The present work has as theme the Aesthetic-Environmental Education and its relations with the conquest of readers since the Kindergarten, To this end, we present as a possibility of this perspective of education, the dramatization of Children's Literature stories for children as a pedagogical practice that can generate significant experiences capable of developing the taste for reading, as well as assisting in the transformative educational practice. We believe as educators that Aesthetic-Environmental Education is "a world of possibilities" (DOLCI, 2014 , p. 32) and that with it we can guarantee the development of human dimensions. Our goal is to reflect and analyze the relationships built by the subjects about the experiences lived with the dramatization of stories, as well as the development of these subjects, after the end of the project. This work comes from a project entitled "Who Counts, Counts, Makes-Believe", which lasted ten weeks in a class with eleven children of level two of Kindergarten, in a municipal public school located in the city of Rio Grande. This is a qualitative research, with exploratory research, with pedagogical intervention procedures, seeking a rethink on educational action and uses content analysis to analyze the generated data. As a result of the analysis we bring three categories, namely: The importance of children's literature in childhood; Why role play stories for children?; The advances perceived throughout the research. We conclude the work bringing the considerations about the conquest of readers since the kindergarten.
\end{abstract}

Keywords: Aesthetic-Environmental Education; Children's Literature; Early Childhood Education; Readers Achievement; Story Role Playing.

\title{
1. Introdução
}

Esta pesquisa emergiu de um projeto intitulado "Quem conta, reconta, faz de conta" realizado em uma escola municipal de Rio Grande/RS com onze crianças de nível dois da Educação Infantil no período de dez semanas, a saber: de agosto a outubro de 2017. O projeto teve o intuito de trabalhar as histórias de Literatura Infantil em uma perspectiva EstéticoAmbiental, para isso, foram contadas dez histórias de Literatura Infantil, uma por semana e todas elas foram dramatizadas, convidando as crianças à interação com a história, além de servir como fio condutor de atividades ao longo das dez semanas.

Durante a realização do projeto cada história foi dramatizada utilizando diferentes linguagens e buscando a interação com as infâncias presentes usamos a música, a dança, o desenho, o imaginário, os fantoches, o teatro, o corpo e a voz, cada uma no seu tempo e no seu contexto. A pesquisa buscou investigar as relações e as interconexões entre a Literatura Infantil e a Educação Estético-Ambiental, dessa forma, procuramos compreender se a maneira como as histórias são contadas para as crianças consegue desenvolver o gosto pela leitura, bem como, 
desvelar como a Educação Estético-Ambiental presente nos momentos de dramatizações de histórias poderia contribuir na formação e desenvolvimento dos sujeitos.

Nós, enquanto pesquisadoras do campo da Educação Estético-Ambiental, acreditamos que a magia e a imaginação fazem parte da forma que a criança lê e interpreta o mundo, dessa maneira, buscamos apresentar as histórias utilizando diferentes linguagens, possibilitando o diálogo com o contexto infantil, visando a compreensão e a assimilação de experiências entre as vivências anteriores e a história que está sendo apresentada, construindo uma teia de significados. Nesse sentido, Cademartori (2010, p. 72), afirma que o texto "apresenta vazios constitutivos que só encontram preenchimento por meio da inserção da faculdade imaginativa do leitor". A intenção era estimular os sujeitos a preencherem esses vazios durante um momento mágico de interação com a história.

A ideia central da pesquisa é compreender que relações se estabelecem entre as crianças e a leitura dramatizada, bem como, desvelar quais as potencialidades que conseguimos desenvolver com essa metodologia de ensino. Isso se justifica por acreditarmos que a imaginação, a afetividade, o lúdico e as relações ativas das crianças com o mundo literário são fundamentais para o desenvolvimento da criança em suas dimensões. Além disso, acreditamos que aprendemos por meio de experiências significadas pelos sujeitos, ou seja, se nos sensibiliza de alguma forma, se desperta emoções e sentimentos, faz sentido para os sujeitos, tornando-se, então, objeto de conhecimento.

Considerando que aprendemos por meio dos nossos sentidos, acreditamos que a Educação Estético-Ambiental é um campo fértil para educação de forma ampla, uma vez que ela "é o processo de desenvolvimento e emancipação das dimensões humanas por meio de experiências significadas em um contexto histórico e social, que propicia a práxis nas relações sociais, políticas e culturais" (DOLCI; MOLON, 2018, p. 801). Vale destacar que essas experiências são estéticas por consequência trata-se de uma educação sensível com foco em construção de experiências que dialoguem com a realidade e a singularidade dos sujeitos.

É uma pesquisa do tipo exploratória, com procedimentos de intervenção pedagógica e os dados coletados foram por meio de observação das pesquisadoras durante a realização do projeto, além de um diálogo com as crianças após o término do projeto e de uma entrevista com a professora regente da turma também após o término do projeto. Sendo assim, a análise desses dados foi realizada com base na análise de conteúdo (BARDIN, 2000; FRANCO, 2007). Os sujeitos integrantes dessa pesquisa receberam carinhosamente o nome de flores a fim de manter o sigilo de suas identidades, bem como por acreditarmos que esse jardim florido e cheio de vida contribuiu com a nossa jornada de conhecimento. 
Da análise dos dados emergiram três categorias que aqui constituem-se enquanto seções desse artigo, a primeira intitulada "A importância da literatura infantil nas infâncias", dialoga com autores e dados da pesquisa que exemplificam a importância que esse contato com a literatura infantil durante a infância, a segunda que nomeamos como: "Por que dramatizar histórias para as crianças?”, versa sobre o que entendemos enquanto dramatizações e dialoga com dados coletados durante a realização da pesquisa, visando compreender os motivos que fazem dessa metodologia um potencial material de trabalho docente, por fim, a terceira e última seção desse artigo recebe o título de "Os avanços percebidos ao longo da pesquisa" e nessa seção apresentamos os principais resultados que as dramatizações de histórias nos proporcionaram.

\section{A importância da Literatura Infantil nas infâncias}

Somos sujeitos históricos e sociais desde que nascemos e isso significa que estamos a todo o momento produzindo e reproduzindo história e cultura. Somos constituídos por nossas relações, nossas experiências, nossos sentimentos e por nossos sentidos. Ao nascer inauguramos nossa jornada de conhecimento que se dá por meio dos nossos muitos sentidos como o tato, o paladar, o olfato, a visão e a audição, nossas experiências começam a gerar sentimentos, que por sua vez determinam nossos gostos e valores, esses sentimentos sejam eles agradáveis ou não, nos ensinam como agir e se relacionar com as pessoas e o mundo.

Na medida em que nos relacionamos com o mundo vamos construindo a nossa história presente no grande livro chamado "vida", também escutamos muitas histórias ao longo da vida, algumas narradas oralmente por pessoas próximas a nós, como as que escutamos em ônibus, mercados e shoppings, têm outras que vemos e observamos acontecer, têm aquelas que fantasiamos em nossa cabeça e torcemos que se tornem reais e têm aquelas que estão escritas em livros por alguém que julgou importante registrar e disseminar em livrarias e bibliotecas para que mais pessoas pudessem desfrutar e aprender com elas.

Sim aprendemos ouvindo, vivenciando e interagindo com histórias, assim como nos diz Abramovich (2006, p. 23) "ouvir histórias pode estimular o desenhar, o musicar, o sair, o ficar, o teatrar, o imaginar, o brincar, o ler o livro, o escrever, o querer ouvir de novo (a mesma história ou outra). Afinal tudo pode nascer de um texto!”, dessa forma, as histórias possuem o potencial de estimular e ampliar o que já temos além de ser um fértil alimento para a curiosidade por aquilo que ainda não conhecemos. Coelho (1993, p. 25) corrobora nesse sentido ao dizer que "no encontro com a literatura (ou com a Arte em geral) os homens têm a 
oportunidade de ampliar, transformar ou enriquecer sua própria experiência de vida, em grau de intensidade não igualada por nenhuma outra atividade.".

Consideramos que a literatura infantil pode ampliar o campo de experiências da criança, assim, quando ela conhece histórias que dialogam com ela, que versam sobre alguma experiência vivida ou sentida por ela, ampliando as possibilidades de ação, ela está fazendo associações que contribuem na sua jornada de conhecimento. Além dessas experiências, temos na literatura outro potencial para a criança, experimentar um mundo ou um contexto histórico e social diferente do seu contribuindo para o enriquecimento de seu repertório linguístico, conceitual e sentimental.

A literatura infantil é capaz de desenvolver o senso crítico e reflexivo dos sujeitos, Cademartori (2010, p. 23) afirma que "o homem constrói seu meio ambiente à medida dos padrões de interpretações que lhe forem oferecidos", ou seja, nossas relações estão imersas a interpretações e conceitos sobre o mundo e as histórias que ele nos conta, portanto, nossa forma de interpretar esse mundo que dialoga a todo tempo conosco, está interligada com os conceitos que gradualmente vamos adquirindo ao longo de nossa jornada que começa na nossa infância. A forma como construímos o ambiente em que estamos imersos, isto é, a forma como interagimos com o nosso mundo tem relação direta com nossos conceitos e leituras de mundo, sendo assim, "a literatura se configura, não só como instrumento de formação conceitual, mas oferece, na mesma medida, elementos que podem neutralizar a manipulação do sujeito pela sociedade"(Ibid, 24).

Para corroborar com as afirmações acima trazemos exemplos de momentos vividos ao longo da pesquisa, como a introdução de elementos presentes nas histórias contadas em suas brincadeiras livres, as crianças traziam as charadas, as músicas e as entonações vocais dos personagens para criar novas brincadeiras e interagir com a turma, essas brincadeiras novas surgiram naturalmente ao longo das semanas. As atividades que foram propostas a partir de cada história geravam também o interesse de recriar as atividades em brincadeiras, dessa maneira, as crianças solicitavam os materiais das atividades para brincarem em momentos diversos. Sendo assim, podemos perceber que as histórias que lhes foram apresentadas passaram a fazer parte do dia a dia das crianças e de sua vida.

É relevante também aqui comentar que segundo Margarida, professora regente da turma, "as crianças possuíam certa resistência no que se refere à literatura", porém, observamos que as crianças começaram a estabelecer relações afetivas com a literatura ao longo da pesquisa, havia períodos em que sentavam no canto referente aos momentos de partilha de histórias e escolhiam livros para que lêssemos para elas. Percebemos que as 
crianças passaram a enxergar o momento de leitura como um momento de prazer e de descobertas, o diálogo entre os leitores e o livro começava a se estabelecer e com isso nasceram questionamentos que nos direcionaram para as pesquisas junto com as crianças da turma. A curiosidade das crianças ao ser ampliada por meio da literatura gerou interesse por novos assuntos, novas descobertas e, principalmente, a vontade de entender os contextos das histórias, gerando momentos de pesquisa na educação infantil.

Manusear, ouvir, conviver e escutar histórias caracteriza-se um momento valioso nas infâncias, trazemos Martins (2006, p. 43) quando afirma que "esses primeiros contatos propiciam à criança a descoberta do livro como um objeto especial, diferente dos outros brinquedos, mas também como fonte de prazer". Perceber o interesse das crianças em ouvir e interagir com cada história, em questionar e buscar saciar as suas dúvidas nos motivou a continuar planejando momentos de curiosidade e de encantamento pelos momentos de leitura, afinal, "esse jogo com o universo escondido em um livro vai estimulando na criança a descoberta e aprimoramento da linguagem, desenvolvendo a sua capacidade de comunicação com o mundo" (Ibid.)

Outro exemplo que serve como subsídio para discutirmos a importância da literatura infantil é que conseguimos perceber o desenvolvimento da autonomia das crianças em resolver as situações-problema que surgiam na turma, com a ampliação do seu repertório linguístico e conceitual, bem como com a liberdade de pensamento que buscamos propiciar, rapidamente as crianças resolviam suas questões de relacionamento, dessa forma, o coletivo tornou-se mais autônomo e unido constituindo sentimentos de afeto e de empatia na turma. Consideramos que o desenvolvimento da comunicação entre os pares auxiliou nessa conquista de autonomia.

Sendo assim, acreditamos que a literatura por si só já se constitui em uma forte aliada da educação, ressaltamos que ela não é importante somente na educação de crianças de educação infantil, mas na educação de crianças, incluindo os anos iniciais, pois possibilita o desenvolvimento das crianças em relação aos seus conceitos e valores. Além disso, acreditamos em um elemento a mais que nos leva a próxima seção desse trabalho, evidenciamos que o potencial da literatura se amplia quando essas histórias são dramatizadas de alguma forma para as crianças, isso porque, ela ganha um considerável aumento em suas dimensões estéticas, aproximando o texto e o mundo, criando a possibilidade que os ouvintes e o texto interajam entre si.

\section{Por que dramatizar histórias para as crianças?}


Vivemos uma realidade desastrosa recheada de intolerâncias, egocentrismos, medos, cobranças, preconceitos e de falta de respeito e empatia pelo próximo. Estamos cercados de informações que chegam a todo o momento pelos meios de comunicação que cada vez aumentam mais em nosso dia a dia caótico. Corremos contra o tempo, estamos sempre atrasados, buscamos saciar nossas necessidades sem pensarmos no outro e sem refletirmos sobre o que estamos fazendo de nossas vidas. Nossa pergunta aqui vem no sentido de reflexão sobre a afirmação anterior, quando corremos contra o tempo não estaríamos nós correndo contra nós mesmos? Esses questionamentos poderiam se alargar a diversas reflexões sobre o mal que fazemos a nós mesmos o tempo todo, muitas vezes sem nos darmos conta de tão grave isso seja, porém não é nosso objetivo nesse momento.

Trouxemos as afirmativas e as reflexões anteriores para identificarmos e exemplificarmos qual realidade que vivemos e que queremos transformar. A Educação Ambiental tem como objetivo formar sujeitos críticos, capazes de elaborar reflexões acerca do mundo vivido, a Educação Ambiental também consiste em uma ação emancipatória que segundo Loureiro (2012, p. 37) “a ação emancipatória é o meio reflexivo, crítico e autocrítico contínuo, pelo qual podemos romper com a barbárie do padrão vigente de sociedade e de civilização, em um processo que parte do contexto societário em que nos movimentamos".

Nesse ínterim, o mundo infantil é recheado de linguagens, a criança que ainda não passou pelo cruel processo de separação do corpo e da cabeça se expressa e dialoga por meio dos seus sentidos. Fazemos a afirmação anterior por acreditarmos que geralmente o sistema escolar cartesiano coloca a criança em um processo de desunião do seu corpo com sua mente, ou seja, para colocar uma criança sentada na mesma posição por quatro horas em uma sala, somente usando seus ouvidos e olhos, esquecendo o resto do corpo, abrindo exceção apenas para a mão segurar um lápis e copiar o conteúdo, é necessário que eles compreendam que ou o seu corpo não dialoga com o mundo ou que as mensagens enviadas pelo seu corpo não são relevantes.

Duarte Jr. (2006, p. 61) nesse mesmo sentido nos diz que "a complexidade de nossa vida, a qual resulta de um entretecer de fatores físicos, metabólicos, sensíveis, emocionais, ambientais, sociais e culturais simplesmente é descartada, e o que resta é um corpo que possui bem pouco de humano", revelando que o sistema educacional ao promover a separação do corpo em partes, passa a considerá-lo como uma máquina que "deve apenas ser consertado por meio de intervenções exteriores, não havendo espaço para sua educação ou reeducação" (Ibid.). Concebendo assim uma educação para a desumanização do corpo. 
Nossa proposta ao pensar nas dramatizações de histórias de literatura infantil é ir contra essa lógica imposta pela modernidade, promovendo o diálogo e a educação sensível, considerando as diversas linguagens e formas de expressão dos nossos alunos, realizando práticas que ajudem a desenvolver essas outras linguagens tão importantes para o ser humano. Além disso, a utilização de diferentes linguagens facilita a aproximação com o mundo e o imaginário infantil, ampliando o processo de ensino e de aprendizagem, bem como o diálogo que consideramos ser inerente à educação.

Utilizamos o termo dramatização de histórias para definirmos o momento de leitura por meio das linguagens, leitura esta, que convida os participantes a interagirem com a história contada. Vale ressaltar que não é necessário teatralizar a história para ser considerada uma dramatização, modificar a entonação vocal para personagens diferentes, utilizar fantoches, preparar o ambiente da história, cantar, dançar, desenhar e adivinhar são alguns exemplos de componentes da dramatização. Em suma, dramatizar histórias significa empregar a multiplicidade de linguagens ao contar uma história, possibilitando a interação e o diálogo entre os sujeitos envolvidos no momento de partilha.

Em relação às linguagens uma definição que se encaixa nessa pesquisa é o sentido de instrumento de comunicação, uma forma de compartilhar mensagens entre os sujeitos, é a nossa forma de nos comunicarmos socialmente. E nos comunicamos de diversas maneiras, pois nosso corpo fala, nossos gestos se expressam em silêncio, nossas feições faciais, o nosso olhar, todo nosso corpo envia mensagens o tempo todo para aqueles que estão ao nosso redor. Pensamos que a linguagem escrita muitas vezes esconde significados que só conseguimos atribuir quando escutamos e observamos alguém falar, são sinais do corpo que enviam mensagens e se comunicam com as pessoas ao redor.

Nesse sentido, cabe ao professor estudar as histórias que vai dramatizar certificando-se que elas atendem aos objetivos da turma, conhecendo seus personagens e as ações que eles desempenham ao longo da história. Afinal, o professor quem vai encenar, sentir e expressar o que o texto significa, sob este aspecto, trazemos Abramovich (2006, p. 18) ao afirmar que "quando se vai ler uma história - seja qual for - para a criança, não se pode fazer isso de qualquer jeito, pegando qualquer volume que se vê pela frente", esse tipo de atitude propicia corrermos muitos riscos em relação a mensagem que estamos apresentando, algumas vezes até, esvaziando o texto de sentido.

As crianças ao vivenciarem uma experiência com a dramatização de histórias criam relações de sentido e de aproximação com a história, para afirmar isso, trazemos algumas falas das crianças provenientes de um diálogo construído após o término da pesquisa, quando, 
por exemplo, Orquídea relata o seguinte: "Eu posso enxergar toda história quando escuto a voz da história”, aqui a voz da história representa a voz dos personagens e a partir dessas vozes ela consegue enxergar com os olhos do imaginário o texto por completo. Também temos a fala da Rosa ao expor a seguinte declaração: "Eu entendo melhor o que acontece na história, quando tem um personagem que fala com uma voz diferente”, conectando internamente que cada personagem é diferente do outro, com traços identitários que compõe os sujeitos, assim como na vida cotidiana e, por fim, apresentamos a fala do Cravo que diz: "Eu acho muito mais legal quando a história tem um personagem, porque não é só a professora lendo um livro", essa afirmação do Cravo nos alerta para contraposição da percepção que a criança possui da ação individual do professor ao pegar um livro e decodificar para as crianças o seu conteúdo e a percepção da ação coletiva que envolve a dramatização de histórias, tornando-se um momento de prazer e divertimento.

Seguindo o pensamento de Dolci (2014, p. 79), “a experiência é significada e faz sentido nas condições históricas do ser humano". Assim, compreendemos que "a experiência compõe a história do sujeito fazendo com que as experiências sejam significadas e permaneçam em sua consciência, pois possuem sentido para ele" (Ibid.). Ainda nesse mesmo sentido e dialogando com os relatos das crianças acerca da experiência vivida, trazemos Smolka (2006, p. 107) quando diz que "a experiência é resultante daquilo que impacta e é compreendido, significado pela pessoa. Há um aspecto compreensivo, apreciativo, valorativo nos sentidos da situação vivida".

Essas reflexões sobre a percepção das crianças sobre a dramatização de histórias mostram a importância de "chamar atenção da criança para as diferenças que a mesma história pode apresentar quando mudamos a forma como vamos contá-la" (KAERCHER, 2001, p. 86), ampliando o repertório de experiências e conceitos das crianças, possibilitando assim, novas ações, valores e assimilações. O que também possibilita a inserção da criança na história, criando um novo fim, questionando algumas ações e refletindo sobre a experiência vivida.

Mas o aspecto mais importante em relação à dramatização de histórias envolve a relação que ela estabelece com a Educação Estético-Ambiental. Ao oportunizar a dramatização de histórias na Educação Infantil, estamos potencializando a formação estética nas crianças, pois as histórias contadas de maneira dramatizada são convidativas para as crianças viverem aquele momento intensamente, uma vez que estimulam a criatividade, a imaginação e a oralidade, facilitando o aprendizado. Compreendemos que a atividade de contar histórias narradas e dramatizadas "promovem o movimento global e fino, trabalham o 
senso crítico, as brincadeiras de faz de conta, valores e conceitos, colaboram na formação da personalidade da criança, propiciam o envolvimento social e afetivo e exploram a cultura e a diversidade" (DE SOUSA; BERNARDINO, 2011, p. 236). Tal posicionamento remete "a um conceito de Educação Estética que pressupõe uma ação educativa em todas as esferas: uma ação integral que propicie a formação de necessidades e interesses culturais e que estimule a criatividade e o desejo de autoaperfeiçoamento" (ESTÉVEZ, 2009, p.30).

Nesse aspecto, ao contar histórias o objetivo está fundamentado no desenvolvimento da sensibilidade estética dos alunos desde a Educação Infantil aos Anos Iniciais do Ensino Fundamental, pois estimula a fantasia, a imaginação, a criatividade, o sonho para que "os seus sentidos transbordem de novas sensações" (ESTÉVEZ, 2009, p.38) e ao criar o espaço propício para este trabalho o professor está contribuindo na formação de personalidades criativas. Contar histórias dramatizadas colabora para que o aluno tenha acesso ao conhecimento sensível, "realizando uma espécie de alfabetização sentimental" (DE SOUZA, 2008, p. 189), propiciando à criança perceber que ela se constitui nas relações sociais, no encontro com o outro (VYGOTSKY, 2000), e não isoladamente em um mundo particular.

No sentido da dramatização de histórias enquanto elemento Estético-Ambiental, a literatura precisa ser vista enquanto agente de reflexão, de transformação e da prática pedagógica que envolve o ato de ler e precisa promover a emancipação por meio dos sentidos humanos. Cademartori (2010. p. 53) ancorada na teoria de Hans Robert Jauss sobre a literatura, diz o seguinte "o leitor é uma força histórica e criadora" e, também, afirma que, "é através do leitor que a obra se incorpora ao horizonte de expectativas de um dado grupo, constituindo-se em agente de mudanças", aquele que se propõe a ler um texto de forma Estético-Ambiental é parte do processo de emancipação que ele se propõe, exercendo um papel de agente transformador.

Portanto, após refletirmos sobre as potencialidades das dramatizações de histórias no contexto dessa pesquisa, nos propomos a analisar os principais resultados e avanços no desenvolvimento das crianças ao longo desse processo, cabe ressaltar que o desenvolvimento não pode ser medido, mas pode ser percebido pelos agentes integrantes desse processo. Nesse sentido, mais do que as nossas observações enquanto pesquisadoras, contamos com a observação da professora regente da turma que os acompanhou desde o início do ano letivo, visto que esta pesquisa foi desenvolvida em um período de dez semanas, correspondendo aos meses de agosto a outubro, tendo a capacidade de avaliar os seus aprendizados.

\section{Os avanços percebidos ao longo da pesquisa}


No decorrer desta escrita já fomos apresentando alguns resultados como subsídios ao diálogo com as teorias que fundamentam essa pesquisa, porém, nesta seção trazemos os principais resultados que obtivemos por meio das dramatizações de histórias. Optamos por reservar nesse artigo uma seção que versa apenas sobre os avanços para que os educadores consigam compreender as potencialidades dessa metodologia Estético-Ambiental. Destacamos que cada turma e cada criança são únicas, dessa forma, nem sempre as mesmas ações com crianças diferentes resultariam nesses dados.

Terminamos o projeto com a construção de um livro que contou nossas experiências e histórias, trata-se de um livro físico com fotos tiradas pelas crianças ao longo das dez semanas ilustrando nossa jornada e com um texto coletivo, escrito pelas crianças e pesquisadoras, que explicava por meio de palavras as experiências e os sentimentos gerados ao longo do processo. Esse livro foi entregue à escola para que fizesse parte de seu acervo e para que as crianças pudessem levar para casa e contar a nossa história para outras pessoas.

As crianças que antes eram resistentes aos momentos de partilha de histórias, modificaram os seus modos de pensar e agir diante das histórias, tornando-se leitores e escritores. $\mathrm{O}$ que começou consistindo em um desafio de escrever cartas de resposta para o nosso personagem Misterioso, percebemos que ao longo do processo transformou-se em prazer, tanto que escrevemos a nossa própria história. Nesse sentido, conseguimos romper com a barreira imposta pelos discursos que surgiram como as expostas na fala de uma criança que ao propormos uma escrita coletiva argumenta que não sabe escrever, logo, não poderia construir um texto.

Além da construção coletiva de textos, inaugurada pela confiança, pelo diálogo e pela ampliação da comunicação com o mundo, também desenvolvemos o gosto pela leitura, antes mesmo que eles pudessem compreender os signos e os símbolos da língua escrita, isso só foi possível, por meio de um planejamento dialógico e desafiador, dialógico no sentido de escutar atentamente as crianças e as suas necessidades e desafiador no que diz respeito ao propormos desafios que rompessem os seus limites e evidenciasse as potencialidades que eles já tinham. Partimos dos argumentos das crianças de não saberem ler e escrever e levamos um livro sem texto escrito, um livro-imagem e propomos que eles lessem aquele livro para nós, todos quiseram participar e contaram histórias diferentes uns dos outros, após esse momento, percebemos que as crianças começaram a "ler" outros livros expostos na sala, mesmo antes da alfabetização.

Os momentos de partilha construídos a partir das dramatizações de histórias de literatura infantil desenvolveram elos entre as crianças e os livros, esses momentos tornaram- 
se importantes e significativos para as crianças evidenciando também um elemento de expectativa daquelas crianças, expectativas essas de aprender, de descobrir, de viver, de conhecer e de se divertir com novos personagens e novos contextos. Percebemos que atingimos o objetivo da Educação Estético-Ambiental uma vez que as crianças aprendiam e se desenvolviam por meio de experiências significadas.

Para corroborar com as afirmações trazemos Margarida que esteve presente em todas as histórias e destaca que "tiveram histórias que transmitiram emoções, curiosidade, conhecimentos e, principalmente, o gosto pelas histórias”. Ela também relata que após o término do projeto as crianças seguiam a cantar as músicas das histórias, a pedir por momentos de histórias com dramatizações e a realizarem atividades mais lúdicas e imaginativas.

Nesse sentido, compreendemos que a imaginação e a ludicidade também foram notavelmente desenvolvidas, algumas crianças que antes estavam fechadas para as brincadeiras imaginativas começaram a compreender que a imaginação e a criatividade abrem portas para sermos o que quisermos ser e o momento da brincadeira se constitui em testes das hipóteses que temos sobre determinado assunto, ou seja, no lúdico podemos testar nossas hipóteses e construir novos conceitos.

Por fim, gostaríamos de destacar o avanço das crianças em relação aos questionamentos e inquietações geradas a partir das histórias, o envolvimento afetivo gerado pelas histórias, bem como as suas interações com os personagens e o mundo mágico que neles estavam envolvidos, auxiliou no desenvolvimento de curiosidades, incentivando a pesquisa, sendo assim, as crianças tornaram-se pesquisadores e nossas pesquisas que surgiram de um questionamento oriundo de uma de nossas histórias, o questionamento era "de onde vem o espirro?" e nos levou à pesquisa sobre o funcionamento do corpo humano e dos seus órgãos, assim como, à confecção de um quebra-cabeça de tecido em formato do corpo humano elaborado pelas crianças e afetuosamente chamado por eles de "Moana".

\section{Considerações sobre a conquista de leitores desde a Educação Infantil}

Todo esse movimento realizado e construído por meio das dramatizações de histórias de literatura infantil nas infâncias nos traz para a conquista do leitor desde a educação infantil, isso porque, acreditamos que para conquistarmos um sujeito leitor não precisamos ensinar os códigos e os símbolos da língua escrita, o que precisamos é que os sujeitos consigam enxergar no livro uma fonte de prazer e descobertas. Quanto mais cedo começarmos esse processo de conquista, mais predispostos serão esses leitores. 
Ler um livro é muito mais do que decodificar palavras, é sentir, viver e compreender os sentidos ali presentes é acima de tudo, imaginar a história a sua maneira. Precisamos imaginar e desenhar a história que estamos lendo ou ouvindo e na Educação Infantil encontramos sujeitos que estão mais propensos ao estímulo da capacidade imaginativa. Além disso, as crianças se comunicam e se relacionam por meio de suas diversas linguagens, tornando assim, as dramatizações um campo valioso para seu desenvolvimento.

Paulo Freire (2009) já nos indica que a leitura de mundo se desenvolve antes da leitura da palavra, dessa forma, desde que nascemos começamos a criar relações com o mundo e inauguramos ao nascer a nossa leitura de mundo. Essa leitura é singular e não existe um método padrão para desenvolvê-la de determinada forma. $\mathrm{O}$ que buscamos nessa pesquisa foi unir as leituras de mundo e as possibilidades de cada um da turma com o gosto pelo mundo literário.

A formação de um sujeito leitor requer a produção de sentidos e de significados ao mundo literário, ele necessita estabelecer relações de afeto e de curiosidade com o mundo que se apresenta nas histórias, nas palavras, no contexto histórico do livro. Acreditamos que as dramatizações de histórias contribuem para o desenvolvimento de familiaridade e de curiosidade por novas histórias, por novos saberes e conhecimentos, bem como contribui para a produção de sentidos ao que apresentamos e propomos enquanto metodologia pedagógica.

A Educação Estético-Ambiental objetiva essa construção de experiências significativas para o sujeito, nesse sentido, a dramatização de histórias enquanto uma possibilidade dessa educação proporciona experiências diversas que buscam interagir com as crianças e construir diálogos que ampliem as diversas leituras de mundo. Esse diálogo permite a curiosidade, a criatividade, a imaginação, os sentimentos e as novas criações, como vimos ao longo desse trabalho. As crianças começam a conceber esses momentos como momentos coletivos de partilha, em que todos são escritores de suas histórias e também fazem parte da história do outro e do mundo.

Ao conquistarmos um leitor já na educação infantil estamos construindo a possibilidade de emergência de novos sujeitos, logo, a emergência de novas possibilidades na educação. Uma criança que desde a mais tenra idade consegue compreender o livro como um mundo de possibilidades, provavelmente tornar-se-á um sujeito crítico e emancipado capaz de "ler" o mundo e os diversos acontecimentos ao seu redor com criticidade. 


\section{Referências}

ABRAMOVICH, Fanny. Literatura Infantil: gostosuras e bobices. $5^{\text {a }}$ ed., São Paulo: Scipione, 2006.

BARDIN, Laurence. Análise de conteúdo. Lisboa, Portugal: Edições 70, 2000.

CADEMARTORI, Ligia. O que é literatura Infantil. $2^{\mathrm{a}}$ ed. São Paulo: Brasiliense, 2010.

COELHO, Nelly Novaes. Literatura Infantil: teoria, análise, didática. São Paulo: Àtica, 1993.

DE SOUSA, Linete Oliveira; BERNARDINO, A. A contação de história como estratégia pedagógica na Educação Infantil e Ensino Fundamental. Revista de Educação, v. 6, n. 12, 2011, p. 235-249.

DOLCI, Luciana. Educação estético-ambiental: potencialidades do teatro na prática docentel Luciana Netto Dolci - 2014. 202 f. Tese (doutorado em Educação Ambiental). Universidade Federal do Rio Grande, programa de pósgraduação em Educação Ambiental, Rio Grande/RS, 2014.

; MOLON, Susana Inês. Educação Estético-Ambiental: o que revelam as dissertações e teses defendidas no Brasil. Revista Ibero-Americana de Estudos em Educação, Araraquara, v. 13, n. 2, p. 785-806, abr./jun., 2018. E-ISSN: 19825587. DOI: 10.21723/riaee.v13.n2.2018.9656

DUARTE JR. João-Francisco. $O$ sentido dos sentidos. $4^{\mathrm{a}}$ ed. Curitiba: Criar Edições Ltda, 2006.

FRANCO, Maria Laura P. B. Análise de Conteúdo. Brasília: Liber Livro Editora, 2007.

FREIRE, Paulo. A importância do ato de ler. 50ª ed. São Paulo: Cortez, 2009.

ESTÉVEZ, Pablo René. A educação estética da personalidade. In: ESTÉVES, Pablo René. A alternativa estética na educação. Traduzido por João Reguffe. - Rio Grande: Ed. da FURG, 2009. P. $27-32$.

KAERCHER, Gládis. E por falar em literatura. In: CRAIDY, Carmem. KAERCHER, Gládis. Educação Infantil, pra que te quero?. Porto Alegre: Artmed, 2001, p. 81-88.

LOUREIRO, Carlos. Trajetórias e fundamentos da Educação Ambiental. $4^{\mathrm{a}}$ ed. São Paulo: Cortez, 2012.

MARTINS, Maria Helena. O que é leitura. São Paulo: Brasiliense, 2006 - (Coleção primeiros passos ; 138)

SMOLKA, Ana Luiza Bustamante. Experiência e discurso como lugares de memória: a escola e a produção de lugares comuns. Pro-posições, v. 17, n. 2, 2006, p. 99-118

VYGOSTKY, L. S. A formação social da mente. $4^{\mathrm{a}}$ ed., São Paulo: Martins Fontes, 2000. 